\title{
Blockchain ve Kripto Paraların Kullanımı Üzerine Bir Değerlendirme
}

\section{An Assessment on the Use of Blockchain and Cryptocurrency}

\author{
Hakan Erkuş ${ }^{a}$, Arif Gümüş ${ }^{b^{*}}$ \\ a Prof. Dr. İnönü Üniversitesi, İİBF, İșletme Bölümü, 44280, Malatya/Türkiye \\ ORCID: 0000-0003-0925-9396 \\ b Öğr. Gör., İnönü Üniversitesi, DVKMYO, D1ş Ticaret Bölümü, 44500, Malatya/Türkiye \\ ORCID: 0000-0002-4865-0892
}

\section{MAKALE BİLGİSİ \\ Makale Geçmişi: \\ Başvuru tarihi: 28 Mayıs 2018 \\ Düzeltme tarihi: 16 Temmuz 2018 \\ Kabul tarihi: 31 Ağustos 2018}

\section{Anahtar Kelimeler:}

Geleneksel Para

Blockchain

Kripto Para
ÖZ

Blockchain teknolojisi, resmi kurumların katkısı olmadan bir ağa bağlı bilgisayarlar aracılığı ile çeşitli onaylama ve doğrulama işlemlerinin gerçekleştirildiği bir sistemdir. 21. yy'da ortaya çıkan blockchain teknolojisi ve kripto paraların hızla yatırım aracına dönüştüğü görülmektedir. $\mathrm{Bu}$ çalışmada blockchain teknolojisinin kullanımı sonucu ortaya çıkan kripto paralar, paranın tarihinden yola çıkılarak incelenmeye çalışılmıştır. Kripto paralar sahip olduğu gücü insanların güveninden alırken, geleneksel para gücünü kendisini piyasaya süren devletten almaktadır. Bu çalışmada kripto paraların güçlü ve zayıf yönleri anlatılarak gelecekte geleneksel para birimi gibi kullanılıp kullanılamayacağı incelenmiştir. Kripto paraların bir para birimi olmaktan çok bir yatırım aracı olarak kullanıldığı görülmektedir. İnsanların bu paralara güveni devam ettiği sürece kripto paraların varlığını koruyacağı, değerinde artış ve azalışlar olacağı gözlemlenmiş, güvenin yok olması durumunda ise etkinliklerini devam ettiremeyeceği tespit edilmiştir.

\section{A B S T R ACT}

Blockchain technology is a system which a variety of validation/authentication and verification operations are performed via computers connected to a network without the contribution of official institutions. The blockchain technology and cryptocurrency that emerged in the 21 st century have turned into investment tools rapidly. Considering the history of the money, this research tries to examine the cryptocurrency which has come into use with blockchain technology. Cryptocurrencies gain strenght depending on people's trust, on the other hand traditional currency gain strenght from the state that put them on the market. In this study, strengths and weaknesses of cryptocurrency are examined and it is investigated if it may be used as a traditional currency in the future. It is known that even though it is a currency, cryptocurrency is used more like an investment vehicle. It is observed that as long as people continue to trust this currency, cryptocurrency will continue to exist with rises and falls in the value, but if the currency loses trust and credibility it is determined that it will not exist anymore.

\section{Giriş}

İnsanlık tarihinin başlaması ile birlikte insanlar, ihtiyaçlarını önce toplayıcılık yoluyla, daha sonra ise kendi ürettikleri ürünler yoluyla karşılamaya çalışmışlardır. İhtiyaç duydukları ve kendileri tarafından üretilmeyen diğer ihtiyaçları ise takas yöntemi ile karşılamışlardır. Çeşitli dönemlerde malın mal ile takası şeklinde kullanılan "mal para", değerli madenlerin bulunması ve bu madenlerin değişim aracı olarak kullanılmaya başlanmasının ardından

* Sorumlu yazar/Corresponding author.

e-posta: a.gumus17@gmail.com
Lidyalıların parayı bulması ile beraber önemini yitirdi. Günümüze kadar birçok maden ve kâğıt, para olarak kullanıldi.

21. Yüzyılın başlarında ortaya çıkan kripto para sistemi, paranın yolculuğunun son halkası olarak karşımıza çıkmaktadır. Kim tarafından ve nasıl piyasaya sürüldüğü tam olarak anlaşılmayan kripto paraların en bilineni olan "Bitcoin", ilk çıktığında değeri "centler" ile ifade edilirken 
günümüzde yüzler hatta binlerce dolarlara çıkmıştır. İnsanlar bu parayı bir yatırım ve değişim aracı olarak görmektedir. $\mathrm{Bu}$ araştırmada para kavramı üzerinde durularak yeni ortaya çıkan kripto paraların para olarak işlem görüp göremeyeceği, avantajları ve dezavantajları ortaya konulmaya çalışılacaktır. Araştırma iki bölümde oluşmakta: birinci bölümde geleneksel paranın tarihçesi ve işleyişi hakkında bilgi verilecek. İkinci bölümde ise blockchain teknolojisinden bahsedilerek kripto paraların ortaya çıkışı, olumlu ve olumsuz yönleri ele alınarak kripto paraların geleneksel para gibi kullanılıp kullanılamayacağı üzerinde durulacaktır.

\section{Para}

\subsection{Paranın Tarihi}

Sosyal, ekonomik ve siyasal bir olgu olan para (Öztürk, 2016: 5), insan ihtiyaçlarının karşılanması gerekliliğinden doğmuştur. Toplayıcılık ve avcılık ile geçinen ilk insanlar kendilerinde olmayan ürünleri ellerinde bulunan ihtiyaç fazlası ürünler ile takas ederek karşılamışlardır. Takas sisteminde, buğday üreten biri kendisinin yapamadığ 1 savaş başlığını almak istediğinde, savaş başlığı üreten kişinin buğdaya ihtiyacı olması gerekiyordu. Takas sisteminin en önemli sorunu takasta kullanılacak malların bir birine karşı değerlerinin tespit edilmemiş olması ve herkesin her an takas edebileceği malları ellerinde bulunduramamasıdır. İşte bu tür sorunların önlenmesi için dünyanın farklı bölgelerinde farklı metalara değişim aracı vasfı yüklenerek sorun çözülmeye çalışılmıştır. Örneğin, Hindistan'ın kıyıya yakın bölgelerinde deniz hayvanı kabuğu, Habeşistan'da Tuz, Virginia'da tütün değişim aracı olarak kullanılmıştır (Ercan, 2005: 126). İlkel dönemlerde yapılan, malın malla takası zamanla malların parayla alınıp satılmasına dönüşmüştür (Berber, Bocutoğlu, 2014: 221).

\subsection{Paranın Tanımı}

Paranın birçok tanımı bulunmaktadır. Sekmen, parayı bir borcun ödenmesi ya da bir malın veya hizmetin alınması sırasında genel kabul gören bir meta ile ödeme işleminin yapılmas1 (Sekmen, 2012: 15) olarak tanımlarken; Özbilen, İnsanların değişim aracı olarak gördüğü güvendiği her şey paradır (Özbilen, 2015: 1) şeklinde tanımlamıştır. Bir başka tanım olarak Parasız parayı, borç ödemelerinde mal ve hizmet alım satımlarında ödeme aracı olarak kullanılan, herkesçe değişim aracı olarak kabul edilen nesneler (Parasız, 1996: 63) şeklindedir.

Bir metanın para olarak değerlendirilip değişim aracı olarak kullanılabilmesi için, herkesçe kabul edilmesi gerekir. Paranın bir değer biriktirme aracı olarak kullanılması onun likit bir servet biçimi olmasından kaynaklanmaktadır (Aren, 2007: 244).

İlkel dönemlerde değişim aracı olarak kullanılan mallar, zamanla değerli madenlerin kullanılmaya başlanması ile ortadan kalkmaya başlamıştır. Altın ve gümüş gibi madenler; taşımasının kolay olması, yıpranma ve bozulma riskinin düşük olması, değer kaybına uğramaması, küçük parçalara bölünüp tekrar birleştirme özelliklerinden dolayı para olarak kullanılmaya elverişlidir. Zamanla altına dayalı sertifikalar piyasaya çıkmış ve alışverişlerde bunlar kullanılmış. Daha sonra banknotlar ve kâğıt paralar ortaya çıkmıştır. Günümüzde paranın yaptığı birçok işlevi yerine getiren araçlar vardır: Çek, senet, elektronik para, kredi kartları, para yerine alışverişlerde kullanılabilen araçlardır.

\subsection{Paranın Fonksiyonları}

\subsubsection{Klasik Fonksiyonları}

\subsubsection{Değişim Aracı Olma}

Para, malların el değiştirmesi için kullanılan bir araçtır. Tarihi belgelerden anlaşıldığı üzere malların el değiştirmesi için önce mal ile mal takas edilmiş, zamanla bu işlem bir değişim aracı kullanılarak gerçekleştirilmiştir. Değişim aracı olarak farklı metalar kullanılmıştır (Berber, Bocutoğlu, 2014: 221). Parayı önemli kılan satın alma gücüdür (Öztürk, 2016: 22). Para, bu satın alma gücünü herkes tarafindan kabul edilmesinden almaktadır. Paranın değişim aracı olarak kullanılabilmesi için, piyasada bütün varlıklar için belirli bir fiyatın oluşması ve işlem maliyetlerinin düşmesi gerekir.

\subsubsection{2. Ölçü Birimi Olması}

Ağırlığın kg, uzunluğun metre, sıvıların lt ile ölçüldüğü gibi ekonomik değerlerin para cinsinden ifade edilmesi gerekir. Piyasada birçok ürün ve bu ürünlere ait fiyatlar bulunmaktadır. Para, bu fiyatları yansıtmak için kullanılır. Ekonomideki mal ve hizmetlerin değer ölçüsü para ile ifade edilmekte bu da "mal para" ile ortaya çıkan işlem maliyetlerini ortadan kaldırmaktadır (Gonnard, 1938: 347).

\subsubsection{Servet Biriktirme Aracı Olması}

Para, bir tasarruf aracı olarak serveti oluşturan bileşenlerden biridir. Kazancın gideri aşan kısmına tasarruf denir. Tasarrufların nakit olarak elde tutulması ve ilerde kullanılmasını sağlayan araç, paradır (Zarakoğlu, 1965: 6). Ancak enflasyon paranın satın alma gücünü düşürür. Aylık geliri 2.000 TL olan bir bireyin $1.500 \mathrm{TL}$ aylık gideri olduğunda aradaki 500 TL'lik fark bireyin tasarrufudur. Enflasyonun yüksek olduğu ülkelerde para, birikim yapma özelliğini kaybeder. İnsanlar bu dönemlerde ulusal para tutmayı tercih etmeyerek gayrimenkullere ya da güvenilir yabancı paralara yönelerek (Gürler, 2013: 201) enflasyonun etkilerinden korunmaya çalışırlar.

Tablo 1. Paranın Fonksiyonlarına Göre Geleneksel Paralar ile Kripto Paraların Karşılaştırılması

\begin{tabular}{|c|c|c|c|}
\hline \multicolumn{2}{|c|}{ Paranın Fonksiyonları } & $\begin{array}{l}\text { Geleneksel } \\
\text { Paralar }\end{array}$ & $\begin{array}{l}\text { Kripto } \\
\text { Paralar }\end{array}$ \\
\hline \multirow{3}{*}{ 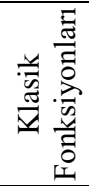 } & a. Değişim Aracı Olma & $\sqrt{ }$ & - \\
\hline & b. Ölçü Birimi Olması & $\sqrt{ }$ & - \\
\hline & c. Servet Biriktirme Aracı Olması & $\checkmark$ & $\checkmark$ \\
\hline \multirow{3}{*}{ 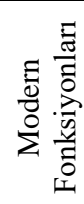 } & $\begin{array}{l}\text { a. Ekonomik Faaliyetleri } \\
\text { Destekleyici veya Köstekleyici }\end{array}$ & $\checkmark$ & - \\
\hline & b. Gelirin Yeniden Dağıtılması & $\sqrt{ }$ & - \\
\hline & $\begin{array}{l}\text { c. Nüfuz Aracı Olarak } \\
\text { Kullanılması }\end{array}$ & $\checkmark$ & - \\
\hline
\end{tabular}




\subsubsection{Modern Fonksiyonları}

\subsubsection{Ekonomik Faaliyetleri Destekleyici veya Köstekleyici}

Paranın Üretimi teşvik etmek, yatırımları finanse etmek gibi ekonomik faaliyetleri kolaylaştırıcı bir işlevi vardır (Parasiz, 2005: 11). Ekonomik faaliyetlerin devam edebilmesi için piyasada yeterli miktarda likiditenin olması gerekir. Para arzında meydana gelen bir artış paranın değerini ve faiz oranlarını düşürecektir. Piyasadan para çekildiğinde ise paranın değeri yükselecek ve faiz oranları artacaktır (Özbilen, 2016: 19).

\subsubsection{Gelirin Yeniden Dağıtılması}

Para finansal kurumlarda toplanır. $\mathrm{Bu}$ paranın gelir dağılımına etkisi kredi kullanıcılarına verilip verilmemesi ile ortaya çımaktadır. Kredi kullanabilen işletmeler, iş hacimlerini ve karların arttıracağı gibi yüksek enflasyonun var olduğu ekonomilerde kredinin geri ödenmesinde de avantajlar elde etmektedirler. Aksine kredi kullanamayan işletmeler bu avantajlardan mahrum olmaktadırlar (Özbilen, 2016: 20).

\subsubsection{Nüfuz Aracı Olarak Kullanılması}

Parayı elinde bulunduran ekonomik birimler nüfuz sahibidirler. Para sahip olmayanları istedikleri şekilde yönlendirme gücüne sahiptirler. Gelişmiş ülkeler gelişmekte olan ülkelere para kaynaklarını kredi olarak kullandırarak bu ülkelerde söz sahibi olmaktadırlar. Son dönemlerde örneklerini daha sıklıkla gördüğümüz paranın bir yaptırım gücü olarak kullanılması zengin ülkelerin dünyada daha fazla söz hakkı elde etmesini sağlarken, bu kaynakları kullanan devletlerin kendi para birimlerinin değersiz hale gelmesine sebep olmaktadır (Özbilen, 2015: 20).

\subsection{Paranın Özellikleri}

Para genel kabul görmelidir. Ekonomide bir nesnenin para olarak işlem görebilmesi için herkes tarafından kabul edilmesi bir değer ölçüsü, bir mübadele aracı, tasarruf aracı ve değer biriktirme aracı olması gerekir (Berber ve Bocutoğlu, 2014: 223). Günümüzde geleneksel paralar herkes tarafından kabul görmekte, karşıllı̆ında hiçbir şey olmamakla birlikte sadece devletlerin varoluş gücüne dayanan paralar kullanılmaktadır.

Piyasada bulunan aynı miktardaki paraların şekli ve özellikleri standart olmalıdır. Para standart bir şekilde üretilmez ise yaygın bir şekilde kullanılmaz (Günal, 2012: 9).

Paranın alışverişte kullanılırken alacak ve borç ödeme işlemleri sırasında ödemenin tam olarak yapılabilmesi için bölünebilmesi gerekir (Öztürk, 2006: 210 ). Mal paranın kullanıldığı dönemlerde en büyük sorun olan bölünebilme sorunu, metal paraların ve kâğıt paraların ekonomiye girmesiyle ortadan kalkmıştır. Böylece alışverişlerde para üstü alma ve yüksek meblağlarda para ödemede oluşan sorunlar çözülmüş̧ür (Öçal vd., 1997: 8).

Paranın bir yerden başka bir yere taşınması kolay olması gerekir. Takas usulünün var olduğu dönemlerde takas yapılacak malların taşınması oldukça zahmetli idi. Daha sonraları kullanılan altın ve gümüş paraların nakledilmesi esnasında çalınması veya kaybolması durumlarında sahibi için büyük kayıplar oluşturuyordu. Günümüzde insanlar kâğıt paraların yerine geçen çek, kredi kartları gibi araçlar kullanarak paranın taşınma sorununu ortadan kaldırmışlardır (Öztürk, 2017: 27).

Paranın kullanılması aşamasında yıpranma ve aşınmalara karşı dayanıklı olması gerekir. Metal ve kâğıt paralar belirli bir süre kullanıldıktan sonra yıpranmaktadır. Paranın yapımında kullanılan materyaller seçilirken mümkün olduğunca bu durum göz önünde bulundurulmalıdır (Özbilen, 2016: 4).

Para olarak kullanılan nesneler kolayca taklit edilememelidir. Parayı piyasaya süren kuruluş taklit edilmemesi için gerekli önlemleri almalıdır ( Öztürk, 2017: 27). Ancak çok eski tarihlerden beri parayı taklit etmeye çalışan kalpazanlar bulunmaktadır (Özbilen, 2016: 5). Paranın taklit edilerek piyasaya sürülmesi neticesinde parayı basan kuruluş ekonomik kayba uğrarken, piyasada fazladan bulunan para enflasyonun yükselmesine sebep olmaktadır.

Piyasada ekonominin işlemesi için yeterli miktarda para bulunmalıdır. Ekonomide büyümeye paralel olarak piyasadaki toplam para miktarın da artması doğal karşılanmaktadır. Ancak piyasanın ihtiyacından daha fazla paranın piyasaya sürülmesi paranın değerinin düşmesine, dolayısı ile de enflasyonun yükselmesine neden olmaktadır (Kesbiç, 2004: 28).

Para değişim fonksiyonunu yerine getirebilmesi için kolay taşınabilmeli ve değeri çok fazla değişmemelidir (Gürler, 2013: 198). Paranın değerini koruması hatta artması istenir. Belirli bir miktarda para ile belirli bir zaman diliminde alınan mal ve hizmetlerin ilerleyen zaman dilimlerinde ya aynı miktarda mal ve hizmet alınması ya da daha fazla miktarda mal ve hizmet alınması arzulanır (Berber, Bocutoğlu, 2014: 223).

Bağımsızlık sembolü olan para, kanunlara dayalı olarak çıkarıldığında yasal para olurlar. Bu şekilde çıkarılan para kendi sınırları içerisinde sınırsız borç ödeme gücüne sahip olur (Öztürk. 2017: 8).

\subsection{Para Sistemleri}

Para sistemleri, bir ekonomide para ve diğer ödeme araçlarının işleyişini gösterir. Bunlar; mal para sistemi ve temsili para sistemidir (Gürler, 2013: 201).

\subsubsection{Mal Para Sistemi}

Mal para insan ihtiyaçlarının karşılanabilmesi için ortaya çıkmıştır. Kıymetli metalardan oluşan mal paranın nominal değeri ile gerçek değeri arasında fark bulunmamaktadır (Sekmen, 2012: 18). Bu sistemde para aynı zamanda bir mal olarak değer görür. İlk çağlarda takas sisteminde kullanılan mallar buna örnek verilebilir. Takas usulü sadece ilkel dönemlerde değil günümüze yakın zamanlara kadar kullanılmıştır. Örneğin Sovyetler birliğinin dağılması ile ortaya çıkan devletler sahip oldukları kaynaklar ile ihtiyaç duydukları malları takas ederek karşılamışlardır (Özbilen, 2015: 9). 


\subsubsection{1. Çift Metal Sistemi}

Fransa'da 19'yy da kullanılan bu sistemde altın ve gümüş aynı anda ödeme aracı olarak kullanılmıştır (Sekmen, 2012: 23). Bu sistem Altın ve gümüşün resmi para olarak kullanıldığı sistemdir (Öztürk, 2016: 47). İki maden arasında sabit bir oran olmakla birlikte küçük alışverişlerde gümüş büyük alışverişlerde altın kullanılmaktaydı.

\subsubsection{Tek Metal Sistemi}

Altın ve ya gümüşten herhangi birinin değişim aracı olarak kullanılmasıdır. $\mathrm{Bu}$ uygulamada gümüş daha önceden kullanılmaya başlanmış para, altın ve gümüşten yapılmıştır (Delice ve Ege, 2016: 10)

\subsubsection{Gümüş Standardl}

Osmanlı imparatorluğunda kullanılan gümüş akçe, bu standarda örnek verilebilir (Sekmen, 2012, 20). Gümüş sadece değişim aracı olarak kullanılmıştır. Ekonomide kullanılan para belirli miktardaki gümüş ile tanımlanmıştır (Gürler, 2013: 202).

\subsubsection{Altın Standardl}

Birinci dünya savaşı öncesine kadar bütün ülkeler, altın para sistemi kullanırken savaş yılları ve sonrasında artan ihtiyaçları karşılamak için bu sistemden vazgeçmiştir (Öztürk, 2016: 50). Bir ülkenin piyasaya sürdüğü banknotların karşılığında altın rezervlerine sahip olması gerekir. Çıkarılan her altına karşılık piyasaya değeri karşılığında para sürülebilir. Böylece enflasyonun önüne geçmiş olunacaktır. Şuan dünyada hiçbir ülke bu sistemi uygulamamaktadır (Aksoy ve Topçu, 2013: 61).

\subsubsection{Altın Kambiyo Sistemi}

Ellerinde yeterli altın rezervi olmayan ülkelerin milli paralarını, altına çevrilebilir bir para birimine dönüştürmeleridir. İkinci dünya savaşından sonra uluslararası rezerv para özelliğini ABD doları kazanmıştır (Öz ve Fidan, 2013: 122)

\subsection{Temsili Para Sistemi}

Altın ve gümüş gibi değerli madenleri temsil ederler. Temsili paralar kullanılmaya başlandıktan sonra piyasadaki altın ve gümüşler merkez bankalarında toplanmış ve bunların karşılığı olarak piyasada kâğıt paralar yer almıştır (Delice, Ege, 2016: 5). Gerektiğinde bu paralar iade edilerek karşılığında muhafaza edilen altın ve gümüş alınabilir (Yıldırım, 2017: 426).

\subsubsection{Altın ve Gümüş Sertifikaları}

Sarraflara emanet olarak verilen altın ve gümüş karşılığında sarraflar, alışverişlerde kullanılsın diye makbuz vermektedirler. Bu makbuzlarla alışverişler yapıldığından, makbuzların da altın ve gümüşü temsil etmesinden dolayı bu paraya temsili para denmiştir (Özbilen. 2016: 13).

\subsubsection{Banknot}

Altın ve gümüş gibi değerli madenlerin bankalara teslim edilmesi karşılığında piyasada kullanılması için banka notları çıkarılmıştır. Bu banknotların karşılığında tamamen altın ve gümüş bulunmamaktadır. Günümüzde banknot çıkarma yetkisi sadece belli kuruluşlara verilmiştir. Banknot paranın basılması için belirli kuruluşlar görevlendirilmiştir. Ülkede ki mal ve hizmet artışına göre bu kuruluşlar para basmaktadırlar (Aren, 2007: 256).

\subsubsection{Kâğıt Para}

Kâğıt para sisteminde kâğıt paranın altın olarak hiçbir karşılığ 1 yoktur ve paranın değeri tamamı ile itibaridir. Günümüzde kullandığımız kâğıt paralara verilen isimdir. Kâğıda değerini veren üzerinde yazılı olan rakamlardır. Bu paraya satın alma gücünü veren hükümetin güvenirliliği ve gücü olmuştur. Kağıt paranın miktarı arttıkça satın alma gücü düşer bu da enflasyona sebep olur (Berber, Bocutoğlu, 2014: 224).

\subsubsection{Bozuk Para}

Gündelik yaşamda kullanılan ve üzerinde yazılı değeri düşük kağıt paralar olarak bilinirler (Al, ve Akar, 2014: 201). Küçük ve küsuratlı ödemelerin yapılmasında kullanılır ve bu toplam piyasada ki paranın \%1-2'sine tekabül eder (Aren, 2007: 263).

\subsection{Kaydi Para Sistemi}

Bankalarda bulunan mevduat hesaplarına dayanarak bankaların oluşturmuş oldukları para sistemidir. Bankalarda açılan hesaplar vadeli ve vadesiz mevduat hesapları olarak ikiye ayrılırlar. Vadeli mevduat hesaplarına yatırılan paralar belirli bir sürenin sonunda elde edilecek faiz geliri ve anaparanın toplamıdır. Süre bitmeden para çekilirse ele geçecek faizin bir kısmından vazgeçilmiş olunur. Vadesiz mevduat hesabında yatırılan paralar ise istendiği zaman kullanılabildiği için herhangi bir faiz getirisi bulunmamaktadır. Müşterilerin bankalardaki hesaplarına karşılık alışverişlerini bankadaki paralarını kullanmadan çekle ödemeleri sonucu hesabın kendisi banka parasıdır (Dinler, 1996: 360). Bankaların oluşturduğu bu para sadece muhasebe kayıtları ile oluşturulmuş olur. Bu sistem bankalardaki mevduat hesaplarında ki paraların zorunlu karşılıklar düşüldükten sonra piyasaya kredi şeklinde para sunulmasıdır. Paranın banka sistemi içinde çıkmadan hesap değiştirdiği bir sanal paradır.

\subsection{Elektronik Para Sistemi}

Kart tabanlı elektronik para ve internet tabanlı elektronik paralardır. Kart tabanlı elektronik paralara kredi kartlarını örnek verilebilir. İnternet tabanlı elektronik paralar ise internet üzerinde alışverişlerde kullanılan ve bankalardan alınıp şahsi bilgisayarlara yüklenerek ve kullanılan dijital paralardır (Öztürk 2016: 64-65).

\section{Blockchain Teknolojisi}

Sanal para, fikri mülkiyet, kimlik bilgileri, özgeçmiş, sözleşmeler ve kişisel veriler gibi insanlar için değerli olan şeylerin merkezi olmayan sanal bir yerde, resmi kurumlarca doğrulanması ve bu doğrulamalar için komisyon ücreti alınmadan teyit edilmesi işlemi, blockchain teknolojisinin temelini oluşturmaktadır (Bridges, 2017: 3). Blokchain yapısı: ticaret, bankacılık işlemleri, lojistik ve sigortacılık 
işlemlerinde problemlerin çözümünü kolaylaştırmakta ve belgelerin (noter gibi) onaylanmasını sağlamaktadır (Mainelli, 2017: 3). Günümüzde bankacılık ve alışveriş gibi hizmetler internet ortamında yapılabilmekte ve bu kayıtların doğruluğu paket programlar tarafindan yapılmaktadır. Blockchain fikri de bu yapılan işlemlerin doğruluğunu teyit etme ve kaydetme işlemi olarak düşünülebilir (Marvin, 2016-17: 2). Blockchain, dünya çapında değer kaynağı olarak düşünülen, erişime karşı güvenli olarak inşa edilen ve sürekli büyüyen dağıtılmış bir veri tabanına sahip bilgi datalarının kaydını tutan bir yapıdır (Seth, 2016: 20).

Blokchain, internet üzerinde verileri güvenli bir şekilde izlemek ve aktarmak için bir şifreleme protokolü veya yazilım yoluyla uygulanan ayrıntılı kurallar grubudur. Blokchain, işlemleri kaydetmek ve doğrulamak için şifrelenmiş bir dijital defter veya veri tabanı (Gibson ve Kirk, 2016: 7) şeklinde de tanımlanabilir. Blokchainde herhangi bir merkez bulunmamaktadır. Kişisel birçok veriyi içeren blokchain başlangıçta güvenli bir kayıt tutma protokolü olarak düşünülmüştür (Bridges, 2017: 5). Bu güvenli yazılıma üçüncü tarafların güvenmesi şarttır (Gibson and Kirk, 2016: 8). Aksi takdirde sistemde güven ve ortaya çıkacak ve istenen verim elde edilmeyecektir. Sistem geçmişi değiştirmediği için, kimlik bilgileri, sağlık verileri, krediler, cezalar gibi işlemler silinmeyecektir (Mainelli, 2017: 5).

Blockchainde temel gaye işlemleri herhangi bir otoriteye ihtiyaç duymadan doğruluğunu onaylamaktır. Günümüzde bir belge notere onaylatılmış olsa dahi ilerde değiştirilebilme imkânına sahipken blokchain'in yapısı bu belgenin değiştirilemeyeceği garantisini verir (Seth, 2016: 21). Bir veriyi silmek için bütün kullanıcılar aynı anda silme işlemini onaylaması gerekir. Ancak bu sanal bir imkânsızlıktır. Yok edilmek istenen bir veri silinse dahi bu veriye eklenen yeni verilerde eklenmiş olduğundan dolayı alternatif bir gelecek oluşacaktır (Bridges, 2017: 5). Veri tabanına bir işlem girildikten, hesaplar güncellendikten sonra kayıtlar değiştirilemez çünkü tüm kayıtlar birbirine bağlıdır (Gibson ve Kirk, 2016: 7). Veri tabanına Kimlik, sağlık bilgileri ve akademik nitelikteki belgelerin onaylanmış birer sureti dijital olarak işlenir (Mainelli, 2017: $5)$.

Blokchain varlıkları tanımlamak için şifreleme karmaları kullanır (Gibson ve Kirk, 2016: 8). Her kullanıcıyı tanımlamak için de bir şifreleme kullanılır. Bir blok zincirinde her bir kullanıcı kendisini tanımlayan 30'dan daha fazla karakterden oluşan bir alfa sayısal bir adrese sahiptir. Kullanıcılar isterlerse kimliklerini gizler isterlerse paylaşabilirler (Mainelli, 2017: 3). Kimlik verilerinin doğrulanması ile yolcu taşıma hizmeti veren bir servisin uygulamasın telefonuna indiren bir kullanıc bu hizmetten faydalanmak için başvurduğunda kimlik bilgileri blockchain teknolojisi ile değerlendirilerek talebi kabul veya reddedilebilmektedir. Aynı şekilde yolcuda sürücünün bilgilerini teyit etmiş olacaktır (Bridges, 2017: 5). Bu işlemi daha sonra bahsi geçen hizmeti talep edenler görebilmektedir.

\subsection{Blockchain Teknolojisinin Dünyada Kullanım Alanları}

Blockchain teknolojisi dünya genelinde merak uyandırmış resmi kurumlarda bu duruma kayıtsız kalmamıştır. İsveç, tapu sicil kayıtları işlemlerinin blockchain teknolojisi üzerinden yapılması için çalışmalar yapmakta, gayrimenkul işlemlerinin alıcılar, satıcılar, bankalar, hükümet gibi tarafları sürecin ilerlemesini buradan takip etmektedirler (Gertrude, 2016: 12). Güney Kore hükümeti de Samsung firması ile kamu hizmetlerinde blockchain teknolojisinin güvenlik, ulaştırma, idari işler gibi hizmetlerde kullanılması için (Sona, 2017), IBM şirketi, HSBC, KBC, Deutsche Bank gibi bankalarla sınır ötesi ticaret işlemler de blockchain teknolojisinin kullanılması için (Martin, 2017), Avrupa'nın önde gelen bankaları ile Deniz taşımacılığında dünyada önemli bir yere sahip olan Maersk Line şirketi bürokrasiyi azaltıp işlemleri hızlandırmak için Teknoloji şirketi olan IBM ile blockchain teknolojisini kullanmak amacıyla (Getrude, 2017) anlaşmalar yapmışlardır. 2016 yılı Eylül ayında Barclays bankası ile İsrail arasında Hint okyanusunda Güney Afrika Kıtasına bağlı bulunan Şeyşeller ülkesine 100.000 dolarlık bir peynir ve tereyağı ihracı için anlaşmışlardır. Bu ihracat işlemleri normalde 10 gün sürerken blockchain teknolojisi ile yaklaşı 4 saatte bitmiştir (Martin, 2017).

Birçok varlık yöntemi, endüstride çalışan yöneticiler işyerlerinin verimliliğini artırmak ve rekabet avantajı yakalamak için blokchain'i incelemektedirler (Gibson ve Kirk, 2016: 7). Estonya 2007'den beri blockchain teknolojisi ile evrensel bir ulusal kimlik şeması işliyor (Mainelli, 2017: 5). Birçok banka blokchain teknolojisini, mevcut işlemleri verimli hale getirmek için araştırmaktadır (Seth, 2016: 21). ABD'deki Finansal İstikrar Gözetim Konseyinin 2016 yılı raporunda blockchain protokolünün kullanılmasının ABD finansal sistemini olumlu etkileyebileceği belirtilmiştir (Gibson ve Kirk, 2016: 12).

\subsection{Kripto Para Madenciliği}

Blockchainde yapılan bir işlem simgelerden oluşan bir algoritma oluşturur. $\mathrm{Bu}$ algoritma içindeki işlem diğer bilgisayarlar tarafından onaylanırsa bir blok oluşur. Oluşan algoritma internette bir haberin detayı için tıkladığımızda adres çubuğunda oluşan ifadelere benzer. Bu algoritmaları çözerek doğruluğunu teyit edip bloklar içine yerleştirmeye madencilik denir. Algoritma doğrulamaları kripto şeklinde bloklarda saklanır. Pear-to-pear yani noktadan noktaya iletişim ile veriler bir noktadan bir noktaya aktarılır ve bunun doğruluğunu madenciler sağlar. Bu algoritmaları çözmek için yüksek işlem hacmine sahip bilgisayarlar gereklidir. $\mathrm{Bu}$ madencilerin hiçbiri tek başına bu verileri kontrol edemez. Ancak hiçbir aracı olmadan bu verileri doğrulayabilir (Mainelli, 2017: 2). Yapılan bu işlem karşılığında bir ücret alınır. Bu ücret blockchain teknolojisi ile üretilen sanal para sistemidir. $\mathrm{Bu}$ madencilik işlemi bilinen maden ocaklarından çıkarılan altınların piyasa sürülmesine benzer (Nakamoto, 2014: 4). Blockchainde bu tür bilgiler ağa bağlı olan bilgisayarlar tarafindan yapılır. Blockchain kullanıcıları, yeni eklenen veriler ile geçmiş verileri kontrol ederek onaylar (Bridges, 2017: 3). Blockchain'in farklı hizmet türlerini oluşturabilecek bir yapısı vardır. Dağıtılmış veri tabanı ile her bir madenci tüm veri tabanına ve bu tabandaki verilerin geçmişine erişebilir. 
Blokchain, verilerinin doğrulanmasını madenciler yapar. Hiçbir madenci bu onaylama ve doğrulamaları yapmada tek başına etkin değildir. Yeni işlemlerin mevcut yapıya eklenmesi ve ağa bağlı madencilerin bunları onaylaması doğal bir protokolün varlığını ortaya koyar. Bu doğrulama ve onaylama işlemlerinin karşılığında madencilere emeklerinin karşılığ 1 olarak bir ödeme yapılır. Bu ödeme nakit olarak değil sanal olarak yapılır ( Aslantaş Ateş, 2016: 357). Böylece sanal para olan kripto para ortaya çıkmış olur. İlk madencilik yapılmaya başlandığında oldukça karlı olan bu işlemin zaman geçtikçe, işlem sayısı arttıç̧a ve algoritmalar zorlaştıkça ayrıca üretilecek kripto paraların sınırlı olmasından dolayı karlılığı düşmektedir. Algoritmaların zorlaşması sürekli daha güçlü bilgisayarların piyasaya çıkmasına sebep olmakta ve eski bilgisayaralar etkinliğini kaybettiği için atıl duruma gelmektedir.

Kripto paraların kullanılarak arbitraj yapılması bu paraların ilk çıktığı dönemlerde kolay olmasına rağmen günümüzde yapılması istenmez. Kripto paraların bir borsadan bir başka borsaya transferi zaman almaktadır. Oysa arbitraj için anlık veya çok kısa bir süre içerisinde farklı ülkelerde oluşan fiyat avantajından yararlanmak istenilir. Kripto paraların türevi şeklinde olan alt coin'lerde daha hızlı para transferi olduğu için bu paralar önerilir (Hepkorucu ve Genç, 2017, 51).

\subsection{Kripto Paralar}

Dijital para biriminin arkasındaki fikirlerden biri geleneksel para biriminin piyasaya etkilerini ortadan kaldırmaktır. Ancak hedeflenen ile gerçekleşen aynı olmamıştır. Altın, gümüş ve dolardan daha değerli olmuştur. Kripto para takip edilemeyen paradır, bu para ticarette kullanılırken karşılığında ne alınıp ne satıldığı bilinmemektedir. Kripto paraların arkasında herhangi bir devlet garantisi de bulunmadığı için bu tür paralara şüphe ile bakılmaktadır. Bir yerden bir yere para transferi yapmaya "hash" denmektedir. Çok sayıda şifreli para şuan piyasada bulunmaktadır. Bunlardan en çok işlem gören dört tanesi: Bitcoin, Ethereum, Ripple, Bitcoincash'dir. İlk Kripto paray1 2008 yılında Satoshi Nakamoto, herhangi bir hükümet ya da resmi kurum olmadan kullanmıştır (Scott, 2016: 54). Bu ismin sahte olduğu bunun arkasında kişi veya kişilerin olduğu düşünülmektedir (Alpago, 2018: 417). Gittikçe daha az üretilmesi planlanmıştır. Paranın değerini, piyasa talebi, dolaşımdaki miktarı, bağımsız merkez bankaları ile hükümetlerin politikaları belirlemektedir. Bitcoin'de para transferleri banka gözetimi yerine kullanıcıların gözetiminde yapılmaktadır. Para gönderme işlemlerinde paranın akışı görülür ancak kimden kime gittiği tespit edilmez (Nakamoto, 2014: 5). Mevcut paraların karşılığında altın, gümüş, petrol veya devlet güvencesi olması gerekir. Bitcoinin karşılı̆̆ında insanların güvencesi vardır. Güven kaybı olduğunda paranın değeri çok hızlı düşer.

Kripto para piyasasının en büyük sanal parası olan Bitcoin insanların güvenine dayanan bir para sistemidir. 2011 yılında Bitcoin'in sanal bankası soyulmuştur (Reid ve Harrigan, 2012: 7). Bu durum kripto paralara olan güveni ciddi şekilde sarsmış olmasına rağmen, çabuk atlatılmış ve tekrar yükselişe geçmiştir. Yasal sınırlar olmadan komisyon ödemeden kripto paralar ülkeler arası dolaşabilir. 2020'ye kadar piyasada bulunacak Bitcoin sayısı 21 milyon civarında olacaktır (Atik vd, 2015: 250). Eğer ekonominin talebi bundan fazla olursa Bitcoin fiyatında da sürekli bir artış yaşanacaktır. Bunu engellemek ve aynı zamanda uzayan bloklardan dolayı yavaşlayan para transferini hızlandırmak için Bitcoin bölünerek Bitcoincash çıkmıştır.

Bitcoin'in bir finansal balon olup olmadığını zaman gösterecektir. Tarihte yaşanmış birçok ekonomik balon bulunmaktadir. Bunlardan biri de Hollanda lale çılgınlığıdır. 17. da ortaya çıkan bu spekülasyon ile insanlar kazançlarını lale soğanlarına yatırmış, fiyatların sürekli artacağını tahmin eden yatırımcıların piyasadaki tüm lale soğanlarını satın alması sonucu lale soğanı fiyatları fahiş fiyatlara yükselerek piyasada para sıkıntısı baş göstermiştir (Oran, 2011: 158). Sonra bir gece ansızın fiyatlar \%95 oranında düşmüş ve insanlar çok büyük zararlarla karşı karşıya kalmıştır. Kripto paralardaki son zamanlarda meydana gelen aşırı değer artışları bu kripto paralara dönük balon yükselişler olabileceği endişesini ortaya koymaktadır. Bitcoin ilk üretilmeye başlandığında düşük güçteki bilgisayarlarda fazla sayıda üretilebiliyordu. Yapılan işlem sayıları arttıkça düşük kapasitedeki bilgisayarların çözemeyeceği algoritmalar ortaya çıkmaya başladı. Bunun sonrasında Bitcoin üreticileri daha güçlü bilgisayarlar satın almaya başladı. Bitcoin üretimi yaparken bu bilgisayarlar elektrik tüketirken diğer yandan soğutma için ayrıca bir enerji tüketimi geçekleştirmektedir.

Tablo 2. Bitcoin'in değerinin yıllara göre değişimi

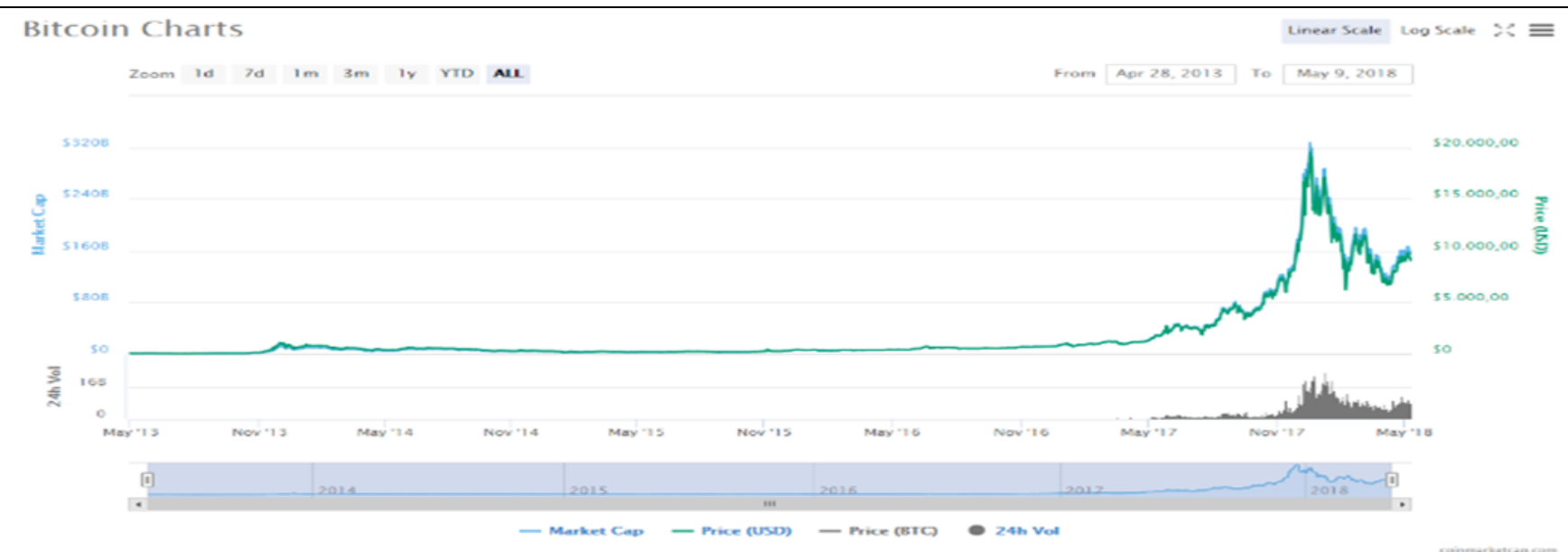




\subsection{Kripto Paraların Üstün ve Zayıf Yönleri}

Geleneksel paralar; herkes tarafindan kabul edilmesi, şekil ve özellikleri aynı olması, bölünebilmesi, taşınabilir olması, yıpranmaya karşı dayanıklı olması, taklit edilememesi, ihtiyaç duyulan miktar kadar piyasada olması, değerini koruyabilmesi ve kanuni bir dayağının olması gerekir. Kripto paralar ise, kanuni bir dayanağı olmayan, sınırlı sayıda üretilen, elle tutulamayan sanal ortamda oluşturulan ve değişim aracı olarak kullanılan varlıktır.

Merkezi Zürih de bulunan dünyanın en büyük finans şirketi olan UBS, kripto paraların varlık veya para olarak değerlendirilemeyeceğini belirtmiştir. Buna gerekçe olarak da fiyatın da ki değişimlerin çok yüksek olmasını ve spekülatif hareketlere maruz kaldığını öne sürmektedir (Hürriyet Gazetesi, 2018). Kripto paralar içinde ki Bitcoin ile ilgili BDDK tarafindan yapılan açıklamada da, resmi ya da özel bir kuruluş tarafindan ihraç edilmeyen ve karşılığ için güvence verilmeyen sanal para birimi olarak bilinen Bitcoin, mevcut yapıs itibariyle elektronik para olarak kabul edilmemektedir (BDDK, 2013) denilmektedir. Kripto paralara talep etmesinin nedeni, insanların para gibi de ğer vermeleridir (Prinççi, 2018: 46). Geleneksel paraların değer kaybetmesine siyasi krizler sebebiyet vermektedir. Bu durum bu paraların arkasında bir kamu otoritesi olduğunu da göstermektedir.

Kripto paralar geleneksel paralarla karşılaştırıldığında üstün ve zayıf yönleri bulunmaktadır.

Kripto paraların üstün üstün yönleri:

(i) Merkez bankaları gibi bağımsız bir yapıya sahiptir, enflasyon ve manipülasyondan etkilenmez (Sönmez, 2014: 11).

(ii) Blockchain yaptığı işlemler ile ilgili doğrulamaları yaparak binlerce dolar tasarruf yaptırabilir (Bridges, 2017: 4). $\mathrm{Bu}$ veriler dünya genelinde kimlik doğrulamada ve diğer işlemlerde kullanılabilir. Bugün her kimlik belgesini onaylama çok yüksek meblağlar tutabilmekte, bu işlemler daha düşük ücretle yapılabilir

(iii) Günümüzde bir yerden bir yere para transferi karşılıklı mutabakatların sağlanması sebebiyle hem uzun zaman almakta hem de maliyetleri yüksek olmaktadır (Meijer, 2016-17: 322). Yurt içi ve yurt dışı para transferlerinde çok az ödemeyle ya da hiç komisyon ödenmeden bu transfer gerçekleştirilebilir. Mevcut sistemde oldukça yüksek komisyonlar ödenmektedir.

(iv) Paranın gönderilmesinde herhangi bir zaman kavramı söz konusu değildir günün herhangi bir saatinde işlem yapılabilir.

(v) Para transferi görülür ancak yapanların kim olduğu bilinmez.

(vi) İşlem hızı, operasyonel verimlilik, şeffaflık ve maliyet azaltma sayılabilir (Meijer, 2016: 323).

(vii) Daha az ofis işlemleri olması, bankacılıktan dolayı alınan komisyonların ortadan kalkması ve daha kısa sürede para transferleri yapılabilmesi (Meijer, 201617: 323) kripto paraların üstün yönleridir.
Kripto paraların Eleştirilen yönleri:

(i) Herhangi bir denetim mekanizmasının olmaması.

(ii) Para arzının sınırlandırılmış olması. Ancak alt coin'lerin çıkması ile bu sorun çözülmüştür.

(iii) Kripto paraların ekonomide kullanılması fiyatının kısa süre içinde yüksek oranda değişmesinden dolayı adil olmayacaktır. Çünkü değeri bir gün yüzde 30 artarken diğer gün bu orandan daha fazla düşebilmektedir (Bridges, 2017: 6). Bu da kripto paraların değişim aracı olarak tercih edilmesini zorlaştırmaktadır.

(iv) Aylık ve günlük dalgalanmalar yatırımcılara ciddi manada zarar veya kar ettirebilmektedir. Örneğin Kripto para birimi kullanılarak bir ay vadeli bir alıveriş yapılmış olsun. Vade sonunda anlaşılan fiyatın birkaç katı fiyatla ödeme yapılabileceği gibi daha düşük bir fiyatta ortaya çıkabilmektedir. $\mathrm{Bu}$ durum diğer para birimlerine göre Kripto paraların değerinin çok hızlı yükselip düşebilmesinden kaynaklanmaktadır.

(v) Kripto paralarla ile uyuşturucu ticareti ve kara para ticaretinin yapıldı̆̆ 1 söylentileri güvenlik güçlerinin dikkatini çekmekte ve tartışmalara neden olmaktadır (Mainelli, 2017: 3).

(vi) Para sınırı olduğundan Kripto paralarla ile kredi çekildiğinde ödemenin yapılmasında problem oluşabilme ihtimali ortaya çıkmaktadır.

(vii)Kripto paraların transferinin izlenememesi nedeniyle vergi kaçakçılığı, kara para aklama ve yasa dışı işlemler ile ilgili topluma zarar verme kayg1s1 vardır (Reid ve Harrigan, 2012: 2).

(viii) Muhasebe işlemlerinde Kripto paralar kullanıldığında sürekli değeri değiştiği için kayıtları tutmak güçleşecektir.

(ix) Mal alım satımlarında Kripto paraların oynak fiyat hareketliliklerinden dolayı firmaları büyük riskler beklemektedir.

(x) Kripto paraların ani fiyat yükselme ve düşmelerine karşı herhangi bir denetim ve kontrol yapıs1 bulunmamaktadır.

(xi) Verilerin sanal ortamda paylaşılması ve bu verilerin şifrelenmiş dahi olsa herkeste bulunması risk oluşturmaktadır (Gibson ve Kirk, 2016: 13).

(xii)Hükümetler için Kripto paralarla yapılan ticarette vergilendirme problemi oluşacaktır.

(xiii) Kanunsuz iş yapan kişiler, yakalandıklarında yasaların mal varlıklarına el koymasını engellemek için Kripto paraları kullanarak mal varlıklarını korumaya çalışabilirler.

(xiv) Diğer para birimleri ile karşılaştırıldığında Bitcoin'in kullanım alanı sınırlıdır.

(xv) Bitcoin'in bilgisayar veya akıllı telefonda bulunan hesap cüzdanları da çalınması veya kaybolması durumunda diğer para birimleri gibi izinin sürülme imkânı yoktur. 


\section{Değerlendirme ve Sonuç}

$\mathrm{Bu}$ çalışmada paranın tarihçesi incelenmiş, para olarak kullanılan değerler açıklanmış daha sonra 21 yy da ortaya çıkan blockchain teknolojisi ve kripto paralar açıklanmıştır. Blockchain teknolojisi, herhangi bir yasal güç olmadan verilerin kaydedilmesi, depolanması ve ihtiyaç duyulan yerlerde kullanılmasını sağlayan bir sistemdir. Bu sistemin kullanımı üzerine devlet ve kurumlar çalışmalar yapmakta ve birçok kurum bu teknoloji ile işlemler yapmaktadır. Gelecekte bu sistemin yaygınlaşacağı öngörülmektedir. Bir kıymetin para olarak kullanılabilmesi için insanların ona değişim aracı olarak güvenmesi gerekmektedir. $\mathrm{Bu}$ kapsamda zaman içinde bu değişim aracı çakıl taşı, tütün, kurutulmuş balık, altın, gümüş, kâğıt ve madeni paralar olmuş son olarak da sanal bir para olmuştur. Günümüz klasik para birimlerinin arkasında bir devlet yönetimi bulunmaktadir. Ancak kripto paralarda herhangi bir devlet gücü bulunmamakta sadece insanların bu oluşumu para olarak görmesinden kaynaklanan bir değeri bulunmaktadır. İnsanların bu sanal para birimine bakışları bu şekilde devam ettiği sürece para olarak işlem görmeye devam edecektir. Ülkeler bu para birimin kullanılmasını kabul ettikçe de daha yasal hale gelecektir. Bu kripto paraların fiyatlarının aşırı oynak olması, arkasında herhangi bir devletin bulunmaması çalınma ve kaybolma gibi risklerden dolayı güven problemi sürekli yaşanmaktadır. Dünya da meydana gelen 2 önemli sanal hırsızlık olayı ciddi şekilde bu paraya olan güveni sarsmış, sonrasında yine toparlanmıştır. Bazı devletlerin bu sanal para birimini kabul etmesi, bazı alışveriş yerlerinin bu paralarla ödemeleri kabul etmesi paranın değerini artıran etkenler olmuştur. Özellikle Japonya'nın kripto paralara karşı pozitif yaklaşımı paranın değerinin yükselmesinde önemli rol oynamıştır. İnsanların bu parayı yatırım aracı olarak görmeleri fiyatlarındaki hızlı yükseliş acaba bir balon mu fikrini de sürekli canlı tutmaktadır. Kısa zaman içindeki dalgalanmaları yüksektir. 2010 yılında 0.03 cent'ten 2018 yılında 20000 dolarlara gelen bir başka para birimi daha yoktur. Bu kadar hızlı yüksek artışın spekülasyona maruz kaldığ 1 fikri akla gelmektedir. Hükümetlerin bu hareketleri tamamen bertaraf edecek bir sistemleri henüz mevcut değildir. Kripto paraların yayılması ve kullanımının artması ülkelerin dikkatinden kaçmamış, bu paranın kullanılış amaçları araştırılmış, yasal ve yasal olmayan sonuçları elde edilmiştir. Özellikle yasalardan kaçan, yasal olmayan işlerin yaptırılması, vergi kaçakçılığı gibi kanunsuz işlerin bu para sistemi ile çok rahat yapılabilecek olması hükümetleri de bu paranın kullanımına karşı araştırmalar yapmaya sevk etmiştir. Çin bu para biriminin ticaretini tamamen yasaklamış bu yasağa uymayanları ağır bir şekilde cezalandıracağını belirtmiştir. Diğer bir Asya ülkesi olan Güney Kore'nin de kripto paraların kullanımını yakın gelecekte yasaklaması beklenmektedir. Kripto paralar Japonya'dan işlem görerek büyük bir destek almıştır.

Önümüzdeki dönemlerde görünecek olan kripto paraların geleneksel paraların yerlerini tamamen alabilmesi zor gibi görünse de bir yatırım aracı olarak en azından varlığını koruyacağı öngörülmektedir. Ancak hükümetlerin vergi gelirleri üzerinden, bankaların transferlerde aldıkları komisyonlar azalacaktır. Ayrıca aşırı enerji tüketimi dolayısı ile dünya genelinde kripto paraların madenciliğine karşı hükümetler önlemler almak zorunda kalacaktır. Ancak kripto paraların tamamen kontrolden uzak yaşam alanı hükümetlerin alacakları önlemler ile yasal bir çerçeveye oturtulmalıdır.

\section{Kaynakça}

Aksoy, M., \& Topcu, N. (2013). Altın İle Hisse Senedi ve Enflasyon Arasındaki İlişki. Atatürk Üniversitesi Íktisadi ve İdari Bilimler Dergisi, 27(1), 59-78.

Al H., \& Akar Ş.K. (2014). Osmanlı Para Reformu, T.C. Merkez Bankası, İstanbul: Denizaltı Osfet.

Alpago, H. (2018). Bitcoin'den Selfcoin'e Kripto Para. Uluslararası Bilimsel Araştırmalar Dergisi, 3(2), 411-428.

Aren, S. (2007). Ekonomi Dersleri. Ankara: İmge Yayınları

Aslantaş, A. B. (2017). Kripto Para Birimleri, Bitcoin ve Muhasebesi. Çankırl Karatekin Üniversitesi Sosyal Bilimler Enstitüsü Dergisi, 7 (1), 349-366.

Atik, M., Köse, Y., Yılmaz, B., \& Sağlam, F. (2015). Kripto Para: Bitcoin ve Döviz Kurları Üzerine Etkileri. Bartın Üniversitesi II BF Dergisi, 6(11), 247-262.

BDDK (2013). Basın Açıklaması. (Erişim Tarihi: 05.08.2018),

https://www.bddk.org.tr/websitesi/turkce/duyurular/Ba sin_Aciklamalari/12574bitcoin_hk_basin_aciklamasi.p df

Berber, M., \& Bocutoğlu, E. (2014). Genel İktisada Giriş. Bursa: Ekin Yayınları.

Bridges, A. (2017). Will Workplaces Be Going Off the Rails on the Blockchain?. (Erişim Tarihi: 05.08.2018), https://www.fisherphillips.com/pp/newsletterarticlewill-workplaces-be-going-off-the-rails-on-theblockchain.pdf?13132

CoinMarketCap (2018). Bitcin. (Erişim Tarihi: 09.05.2018), http://coinmarketcap.com/currencies/Bitcoin/\#charts,

Delice, G., \& Ege, İ. (2016), Para-Banka-Kredi ve Finansal Işlemler. Ankara: Gazi Kitapevi.

Dilek, Ş. (2018). Blockchain Teknolojisi ve Bitcoin. Kriter Dergisi, (231).

Dinler, Z. (1996). İktisada Giriş. İstanbul: Ekin Kitapevi.

Ercan, F. (2015). Para ve Kapitalizm. İstanbul: Devin Yayınlar1.

Forbes (2013). How Bitcoin Works. (Erişim Tarihi: 14.11.2017),

https://www.forbes.com/sites/investopedia/2013/08/01/ how-bitcoin-works/

Gertrude, C. D. (2016). Sweden Tests Blockchain Technology for Land Registry. (Erişim Tarihi: 16 Haziran 2016), https://www.reuters.com/article/ussweden-blockchain/sweden-tests-blockchaintechnology-for-land-registry-idUSKCN0Z22KV

Gibson, C., \& Tyler, K. (2016). Blockchain 101 For Asset Managers. The Investment Lawyer Covering Legal and Regulatory Issues of Asset Management, 23 (10). 
Gonnard, R., \& Suvla, R. Ş. (1938). Paranın Fonksiyonları. İstanbul Üniversitesi Hukuk Fakültesi Mecmuası, 4(14), 346-360.

Günal, M. (2012). Para ve Finansal Sistem. Ankara: Berikan Yayınevi.

Gürler, Z. (2013). Genel Ekonomi. Ankara: Nobel Yayınları.

Hepkorucu, Ö. G. A., \& Genç, Ö. G. S. (2017). Finansal Varlık Olarak Bitcoin'in İncelenmesi Ve Birim Kök Yap1s1 Üzerine Bir Uygulama. Osmaniye Korkut Ata Üniversitesi Iktisadi ve İdari Bilimler Fakültesi Dergisi, 1(2), 47-58.

Hürriyet Gazetesi (2018). UBS Stratejisti'nden Bitcoin değerlendirmesi. (Erişim Tarihi: 03.08.2018), http://www.hurriyet.com.tr/ekonomi/ubsstratejistinden-bitcoin-degerlendirmesi-40917497

Kesbiç, C. Y., Baldemir, E., \& Bakımlı, E. (2004). Bütçe Açıkları İle Parasal Büyüme ve Enflasyon Arasındaki İlişki: Türkiye İçin Bir Model Denemesi. Atatürk Üniversitesi İktisadi ve İdari Bilimler Dergisi, 19(1), 81-98.

Mainelli, M. (2017). Blockchain Will Help Us Prove Our Identities In A Digital World, Harvard Business Review. (Erişim Tarihi: 14.04.2018), https://hbr.org/2017/10/smart-ledgers-can-help-usreclaim-control-of-our-personal-data.

Martin, A. (2017). Banks Team Up With IBM in Trade Finance Blockchain. Financial Times, October 4. (Erişim Tarihi: 03.08.2018), https://www.ft.com/content/7dc8738c-a922-11e7$93 \mathrm{c} 5-648314 \mathrm{~d} 2 \mathrm{c} 72 \mathrm{c}$

Marvin, R. (2017). Blockchain: The Invisible Technology That's Changing the World. (Erişim Tarihi: 14.04.2018), https://software.org/wpcontent/uploads/Software_Beyond-Bitcoin.pdf

Meijer, C. R. (2016). Blockchain and the securities industry: Towards a new ecosystem. Journal of Securities Operations \& Custody, 8(4), 322-329.

Nakamoto, S. (2008). Bitcoin: A peer-to-peer electronic cash system. (Erişim Tarihi: 14.11.2017), https://bitcoin.org/bitcoin.pdf

Oran, A. (2011). Balonları Daha İyi Tanımaya Çalışmak: Balon Tanımları, Modelleri ve Lale Çılgınlığı Örneği. Dokuz Eylül Üniversitesi Iktisadi ve İdari Bilimler Fakültesi Dergisi, 26 (1), 151 - 161.

Öçal, T., Çolak, Ö. F., Togay, S., \& Eser, K. (1997). Para Banka Teori ve Politika. Ankara: Gazi Kitapevi.

Öz, E., \& Fidan, A. (2013). Türkiye'de Altın Bankacılığ1 Faaliyetleri ve Vergilendirmesi. Maliye Dergisi, 164, 120-130.

Özbilen, Ş. (2015). Para Teorisi. Ankara: Gazi Kitapevi.

Öztürk, N. (2016). Para Banka Kredi. Bursa: Ekin Yayınlar1.
Öztürk, N., \& Koç, A. (2006). Elektronik para, diğer para türleriyle karşılaştırılması ve olası etkileri. Sosyal Ekonomik Araştırmalar Dergisi, 6(11), 207-243.

Parasız, İ. (1996). İktisada Giriş. Bursa: Ezgi Kitapevi.

Parasız, İ. (2005). Para Banka ve Finansal Piyasalar. Bursa: Ezgi Kitapevi.

Parasız, İ. (2011). Türkiye'de ve Dünya'da Bankacıllk. Bursa: Ezgi Kitapevi.

Parker, T. (2016). Bitcoin Maybe The Currency Of The Future. (Erişim Tarihi: 14.11.2017), https://www.investopedia.com/financialedge/0212/bitcoin-may-be-the-currency-of-thefuture.aspx

Pirinççi, A. E. (2018). Yeni Dünya Düzeninde Sanal Para Bitcoin'in Değerlendirilmesi. International Journal of Economics Politics Humanities and Social Sciences, 1 (1), 45-52.

Reid, F., \& Harrigan, M. (2013). An analysis of anonymity in the bitcoin system. In: Security and privacy in social networks (pp. 197-223). New York, NY: Springer.

Scott, N. (2016). Blockchain: the internet's second generation. (Erişim Tarihi: 14.11.2017), https://www.director.co.uk/blockchain-internetssecond-generation-19926-2/

Sekmen, F. (2012). Para Teorisi, Kavram-KuramlarModeller. Ankara: Seçkin Yayınevi.

Seth, A. (2016). The Possibilities With Blockchains Explaning Software. (Erişim Tarihi: 14.08.2017), https://opensourceforu.com/

Sönmez, A. (2014). The Turkish Online Jurnal Of Design, Art And Communication, TOIDAC, 4 (3).

Su-Hyun, S. (2017). Samsung SDS wins blockchain project from Seoul Metropolitan Govt. The Korea Herald, Nov 26. (Erişim Tarihi: 26.11.2017) http://www.koreaherald.com/view.php?ud=201711260 00153

Tekinsoy, P. N. (2014). Para Koçluğu. İstanbul: Profil Yayınları.

Yıldırım, K. (2017). İktisada Giriş. Eskişehir: Nisan Yayınları.

Zarakoğlu, A. (1965). Para ve Banka. Ankara: Yeni Desen Tic. Ltd. Şti. Matbaası. 